\title{
Article \\ Chronic Nutrition Impact Symptoms Are Associated with Decreased Functional Status, Quality of Life, and Diet Quality in a Pilot Study of Long-Term Post-Radiation Head and Neck Cancer Survivors
}

\author{
Sylvia L. Crowder ${ }^{1,2, * \mathbb{C}}$, Zonggui Li $^{3}{ }^{3}$, Kalika P. Sarma $^{4}$ and Anna E. Arthur ${ }^{1}$ (i) \\ 1 Department of Food Science and Human Nutrition, University of Illinois at Urbana-Champaign, \\ 386 Bevier Hall 905 S Goodwin Ave, Urbana, IL 61801, USA; aarthur@illinois.edu \\ 2 Department of Health Outcomes and Behavior, Moffitt Cancer Center, 4117 E Fowler Ave, \\ Tampa, FL 33617, USA \\ 3 Department of Psychology and Neuroscience, Boston College, 140 Commonwealth Ave, \\ Chestnut Hill, MA 02467, USA; il@bc.edu \\ 4 Carle Cancer Center, Carle Foundation Hospital, 602 W University Ave, Urbana, IL 61801, USA; \\ Kalika.sarma@carle.com \\ * Correspondence: sylvia.crowder@moffitt.org; Tel.: +1-217-244-4090
}

\section{check for}

updates

Citation: Crowder, S.L.; Li, Z.; Sarma, K.P.; Arthur, A.E. Chronic Nutrition Impact Symptoms Are Associated with Decreased

Functional Status, Quality of Life, and Diet Quality in a Pilot Study of Long-Term Post-Radiation Head and Neck Cancer Survivors. Nutrients 2021, 13, 2886. https://doi.org/ 10.3390/nu13082886

Academic Editor: Henry J. Thompson

Received: 28 July 2021

Accepted: 20 August 2021

Published: 22 August 2021

Publisher's Note: MDPI stays neutral with regard to jurisdictional claims in published maps and institutional affiliations.

Copyright: (c) 2021 by the authors. Licensee MDPI, Basel, Switzerland. This article is an open access article distributed under the terms and conditions of the Creative Commons Attribution (CC BY) license (https:// creativecommons.org/licenses/by/ $4.0 /)$.
Abstract: Background: As a result of tumor location and treatment that is aggressive, head and neck cancer (HNC) survivors experience an array of symptoms impacting the ability and desire to eat termed nutrition impact symptoms (NISs). Despite increasing cancer survival time, the majority of research studies examining the impact of NISs have been based on clinical samples of HNC patients during the acute phase of treatment. NISs are often chronic and persist beyond the completion of treatment or may develop as late side effects. Therefore, our research team examined chronic NIS complications on HNC survivors' functional status, quality of life, and diet quality. Methods: This was a cross-sectional study of $42 \mathrm{HNC}$ survivors who were at least 6 months post-radiation. Selfreported data on demographics, NISs, quality of life, and usual diet over the past year were obtained. Objective measures of functional status included the short physical performance battery and InBody® 270 body composition testing. NISs were coded so a lower score indicated lower symptom burden, (range $4-17$ ) and dichotomized as $\leq 10$ vs. $>10$, the median in the dataset. Wilcoxon rank sum tests were performed between the dichotomized NIS summary score and continuous quality of life and functional status outcomes. Diet quality for HNC survivors was calculated using the Healthy Eating Index 2015 (HEI-2015). Wilcoxon rank sum tests examined the difference between the HNC HEI-2015 as compared to the National Health and Nutrition Examination Survey (NHANES) data calculated using the population ratio method. Results: A lower NIS score was statistically associated with higher posttreatment lean muscle mass $(p=0.002)$. A lower NIS score was associated with higher functional ( $p=0.0006)$, physical $(p=0.0007)$, emotional $(p=0.007)$, and total $(p<0.0001)$ quality of life. Compared to NHANES controls, HNC survivors reported a significantly lower HEI-2015 diet quality score $(p=0.0001)$. Conclusions: Lower NIS burden was associated with higher lean muscle mass and functional, physical, emotional, and total quality of life in post-radiation HNC survivors. HNC survivors reported a significantly lower total HEI-2015 as compared to healthy NHANES controls, providing support for the hypothesis that chronic NIS burden impacts the desire and ability to eat. The effects of this pilot study were strong enough to be detected by straight forward statistical approaches and warrant a larger longitudinal study. For survivors most impacted by NIS burden, multidisciplinary post-radiation exercise and nutrition-based interventions to manage NISs and improve functional status, quality of life, and diet quality in this survivor population are needed.

Keywords: survivorship; head and neck; diet; symptoms; quality of life 


\section{Introduction}

Head and neck cancer (HNC) is a heterogeneous disease including cancer of the oral cavity, oropharynx, hypopharynx, and larynx [1]. As a result of treatment and treatment that is aggressive, HNC survivors experience an array of symptoms impacting the desire and ability to eat termed nutrition impact symptoms (NISs) [2]. Common NISs include dysphagia, xerostomia, and difficulty chewing that lead to comprised food intake, malnutrition, and increased susceptibility to infection [2-4]. HNC survivors are living longer, thus increasing the survivorship period [2,5]. Despite increasing cancer survival time, the majority of research studies examining the impact of NISs have been based on clinical samples of HNC patients during the acute phase of treatment. NISs are often chronic and persist beyond the completion of treatment or may develop as late side effects [2]. Therefore, it is crucial for healthcare providers to examine chronic NIS complication on survivors' functional status, quality of life, and diet quality.

While it has previously been established that the time around formal diagnosis until approximately three months post-treatment has been associated with decreased quality of life, little is known regarding the chronic burden, defined as greater than 6 months, of treatment-related outcomes in HNC survivors [6]. Quality of life is a measure of survivors overall well-being and often encompasses several domains-functional, physical, social, and emotional health. HNC is considered as one of the most emotionally traumatic cancer types [7] and impacts quality of life outcomes [8,9]. Studies have identified anxiety [10], depression [11], and psychological problems [12] in HNC survivors to be associated with poorer quality of life. However, few studies have examined the chronic impact of aggregated NIS burden on overall and domain-specific quality of life and functional status. This is of the upmost importance as one of the most important quality of life factors is nutrition [13] and adaptations to eating and psychological concerns regarding dysphagia and xerostomia may further reduce functional status in survivors $[2,14,15]$. The HNC population faces unique nutritional challenges as compared to other cancer types, likely decreasing functional status and quality of life.

Before interventions can be designed to enhance survivorship outcomes of long-term survivors, data is needed to inform researchers that provides evidence of reduced quality of life, functional status, and diet quality in long-term HNC survivors that identify critical targets for interventions. Therefore, the objective of this pilot study was to evaluate the relationship between an NIS summary score on quality of life and functional status and compare the diet quality of post-radiation head and neck cancer (HNC) survivors to age-matched National Health and Nutrition Examination Survey (NHANES) controls.

\section{Subjects and Methods}

\subsection{Design}

This was a cross-sectional study of $42 \mathrm{HNC}$ survivors who were previously diagnosed or treated in a Midwestern hospital within six months to nine years post treatment. In the quality of life model, the dependent variables of interest were total, emotional, physical, functional, and social quality of life. In the functional status model, the dependent variables of interest were body mass index, functional status composite score, body fat percentage, and lean muscle mass. The independent variable of interest was aggregated NIS burden reflected by a dichotomized NIS summary score. Dietary intake for HNC survivors was assessed using the Healthy Eating Index-2015 (HEI-2015) [16] collected with the semiquantitative Harvard food frequency questionnaires (FFQ) [17] as compared to NHANES controls using the population-ratio method [18]. All study activities were approved by the Institutional Review Boards of Carle Foundation Hospital and the University of Illinois at Urbana-Champaign (Project ID: 17088; UIUC number: 181933; Original Approval Date: 1 February 2018) and adhered to the principles of the Declaration of Helsinki. All participants were informed of the purpose and procedures of the study and informed written consent was obtained from all participants before data collection. 


\subsection{Study Population}

Participant screening and recruitment occurred between March 2018 and May 2019. Criteria for eligibility included: (1) Previous diagnosis of stage I-IV primary cancer of the oropharynx, hypopharynx, larynx, or oral cavity; (2) within 6 months to 10 years posttreatment with radiation; (3) no evidence of disease, deemed by oncologist and/or surgeon; (4) ability to consume food orally; (5) $\geq 18$ years of age; and (6) English-speaking. HNC survivors treated at the hospital were identified via the Hospital Cancer Registry and a letter was mailed to potential participants explaining the research study. Participants were called within 2-3 weeks of receiving the mailed letter. Medical records were searched to prevent calling deceased individuals. Interested participants were then scheduled for an in-person study visit. At the study visit, formal written consent was obtained.

\subsection{Procedures}

Participants completed a self-administered health survey that included data on demographics, behavioral characteristics, quality of life, and NIS burden. Dietary data were obtained using the self-administered 2007 Harvard FFQ [17,19,20]. Functional status data were obtained using the short physical performance battery [21] and InBody® body composition testing [22]. An electronic medical record (EMR) review was conducted to collect clinical data on cancer stage, treatment type, and time since diagnosis. Participants were compensated $\$ 50$.

\section{Measures}

\subsection{Predictor: Nutrition Impact Symptoms}

The Functional Assessment of Cancer Therapy-Head and Neck (FACT-H\&N) Additional Concerns (AC) Subscale was used to measure perceived NIS barriers [23]. The scale consists of 12 questions, six specifically referring to NIS including: (1) ability to eat any foods desired, (2) ability to eat as much as desired, (3) no presence of xerostomia, (4) ability to swallow naturally and easily, (5) ability to eat solid foods, and (6) no presence of pain in the mouth, throat, or neck, with answers ranked on a 5-point Likert scale ranging from 0 (not at all) to 4 (very much). The scale was coded so that a lower score indicated fewer disease- or treatment-related symptoms. The individual symptom scores were summed to create a total overall NIS summary score (range $4-17$ ) and dichotomized as $\leq 10 \mathrm{vs.}>10$, the median in the dataset.

\subsection{Outcome Variable: Functional Status}

A study team member trained in anthropometrics collected the following functional status measures: anthropometrics, bioelectrical impedance analysis (BIA) [22], and the short physical performance battery [21].

Anthropometric measures for height were conducted in accordance with the Anthropometric Standardization Reference Manual [24]. Height was collected by a trained research staff member during the study visit and measured to the nearest 0.5 inch (without shoes).

Measures of body composition were determined by a vertical direct segmental multifrequency BIA analyzer (InBody@ 270, Cerritos, CA, USA). The InBody@ 270 records a user's weight, lean muscle mass, body mass index, and percent body fat to the nearest $0.1 \mathrm{lb}$ (without shoes and in light clothing with pockets emptied). The method of measuring body composition via a BIA has been previously validated and used in similar clinical studies [22]. Four participants were unable to complete InBody® ${ }^{\odot}$ measures as a result of other health conditions (pacemakers and physical impairments).

The short physical performance battery consists of three functional tests assessing performance. The physical performance battery has been previously used in the HNC population [21]. Tests of standing balance include tandem, semi-tandem, and side-by-side stands. Walking speed tests included an 8-foot walking course, with no obstructions for an additional two feet at either end. Participants were allowed to use assistive devices when needed, and each participant was timed for two walks [25]. To test the ability to 
rise from a chair (termed chair rise-and-sits), a straight-backed chair was placed next to a wall; participants were asked to fold their arms across their chest and to stand up and sit down five times as quickly as possible [25]. Participants were timed from the initial sitting position to the final sitting position at the end of the fifth stand. The short physical performance battery provides a summed composite score based on the number of seconds able to hold a semi-tandem, tandem, and/or side-by-side stance with feet together; 8-foot walk time; and time to complete 5 chair rise-and-sits [25].

\subsection{Outcome Variable: Quality of Life}

Overall quality of life was assessed using the FACT-H\&N quality of life questionnaire (Cronbach's coefficient alpha $=0.86$ ) [23]. The FACT-H\&N assesses the impact of cancer diagnosis and therapy in four subdomains: physical, social, emotional, and functional. The FACT-H\&N has 28 questions, with answers ranked on a 5-point Likert scale ranging from 0 (not at all) to 4 (very much). The scale was coded so that a higher score indicated higher quality of life. Questions were summed to create four subdomain scores and the four subdomains were summed to create a continuous total summary score.

\subsection{Outcome Variable: Dietary Intake}

HNC survivors' dietary intake information was collected using the validated 131 item semi-quantitative Harvard Food Frequency Questionnaire, which includes standard portions sizes for each item and the frequency of consumption over the past year [26]. The Harvard FFQ is a feasible instrument suited to assess associations of usual dietary intake and has been extensively used as a measure of dietary exposure in cancer studies [27]. The FFQ allows participants to choose the average frequency of consumption of food items over the past year from a Likert scale. Healthy eating of the HNC survivors was assessed using the HEI-2015 dietary measurement and compared to the NHANES controls using the population ratio method $[16,28]$. This method was employed because advice from the Dietary Guidelines for Americans (DGA) is designed to be met over time and this method best encompasses that intent for diet evaluation [29]. The HEI was developed to assess diet quality issued by the United States Department of Agriculture (USDA) based on the standards of a healthy lifestyle in association with health outcomes [30]. HEI is composed of 13 scored components and include 5 major food groups: fruit (total and whole), vegetable (total and greens/beans), grains (total and whole), dairy or alternative dairy and protein, oils, and nuts; in addition to limiting saturated fats, sodium, and empty calories [16]. Nine of the components focus on adequacy (dietary components to increase) and four focus on moderation (dietary components to decrease, including refined grains, sodium, added sugars, and saturated fats) [16]. The daily intakes for each component were standardized for energy by diving each study participant's daily component intake by his or her total daily energy intake in kilocalories and multiplying by 100 prior to applying the HEI-2015 scoring algorithm [16]. Each of the 13 components of the HEI-2015 had a minimum score of zero and a maximum score ranging from 5 to 10 that reflected a pre-established level of intake [16]. The total HEI score is the sum of the components, with a range of 0 to 100 [16]. A score between 0 and 50 indicates a poor diet; 51 and 80, a moderate diet quality that needs improvement; and a score greater than 80, a good diet [16].

\section{Statistical Considerations and Analyses}

Descriptive statistics (means and frequencies) were generated for demographic and clinical variables. ANOVA tests were computed to detect statistical difference between quality of life and demographic variables. The FACT-H\&N scoring manual was used to calculate the mean score and standard deviations [31]. Summary scores and subscale scores were extracted into three tertiles of the actual range of scores and categorized as mild, moderate, or severe using methods described in similar studies [32,33]. For example, in the FACT-G, the actual range is 0 to 108; therefore, the three tertiles were $0-36$ as severe impairment, 37-72 as moderate impairment, and 73-108 as mild impairment [33]. 
For the functional status model, Wilcoxon rank sum tests between lean muscle mass, body fat percentage, body mass index, and functional status and the dichotomized NIS summary score were computed. For the quality of life model, Wilcoxon rank sum tests between subdomain and total quality of life measures and the dichotomized NIS summary score were computed. Wilcoxon rank sum tests examined the difference among HNC HEI-2015 as compared to NHANES controls using the population ratio method. Statistical significance was set as an alpha level $<0.05$. Statistical analyses were performed using SAS software, version 9.4 or later [34].

\section{Results}

\subsection{Participant Characteristics}

The overall demographic characteristics of the study population are shown in Table 1. The mean age of the study population was 62 years old, and most participants were married (57\%). Most participants were white males (59.5\%), with at least some college education $(62 \%)$. The most common tumor location was the oral cavity, and most participants were diagnosed with stage III-IV cancer $(30 \%)$. The majority of participants were $1-4$ years post treatment $(64 \%)$. The majority were former smokers $(57 \%)$ and current alcohol users (48\%). Accrual was met within 14 months and required screening of $266 \mathrm{HNC}$ cases. Of these, 79 were eligible for study participation and 187 were ineligible or excluded. Of the 79 eligible HNC cases, 42 agreed to participate for an enrollment rate of $52.2 \%$. Reasons for ineligibility were distance $(N=15)$, timing $(N=13)$, too sick $(N=6)$, and too busy $(N=3)$.

Table 1. Demographic and clinical characteristics $N=42$.

\begin{tabular}{lc}
\hline \multicolumn{1}{c}{ Characteristic } & Total Participants \\
\hline Age: Mean \pm SD [range], years & $62.7 \pm 11.8(32-81)$ \\
Body Mass Index: Mean \pm SD [range], $\mathrm{kg} / \mathrm{m}^{2}$ & $26.2 \pm 4.85(16.5-38.3)$ \\
\hline Under/normal weight $N(\%)$ & $21(50.0)$ \\
Overweight/obese $N(\%)$ & $21(50.0)$ \\
\hline Lean muscle mass ${ }^{\mathrm{a}}: N(\%)$ & \\
Under/normal & $27(71.0)$ \\
High & $11(29.0)$ \\
\hline Body fat percentage ${ }^{\mathrm{a}}: \mathrm{N}(\%)$ & \\
Under/normal & $13(34.2)$ \\
High & $25(65.8)$ \\
\hline Gender: $N$ (\%) & \\
Male & $25(59.5)$ \\
Female & $17(40.5)$ \\
\hline Ethnicity: $N(\%)$ & \\
Non-Hispanic & $42(100)$ \\
\hline Race: $N$ (\%) & \\
European American/White & $39(92.9)$ \\
Other & $3(7.1)$ \\
\hline Education: $N$ (\%) & \\
High school or less & $16(38.1)$ \\
Some college or more & $26(61.9)$ \\
\hline Annual household income: (dollars/year) $N(\%)$ & \\
Less than $\$ 54,999$ & $24(57.1)$ \\
\$55,000 or more & $18(42.9)$ \\
\hline Marital Status: $N(\%)$ & \\
Married & $24(57.1)$ \\
Not married & $18(42.9)$ \\
\hline
\end{tabular}


Table 1. Cont.

\begin{tabular}{lc}
\hline \multicolumn{1}{c}{ Characteristic } & Total Participants \\
\hline Smoking Status: $N(\%)$ & $3(7.1)$ \\
Current & $24(57.2)$ \\
Former & $15(35.7)$ \\
Never & \\
\hline Alcohol Status: $N(\%)$ & $20(47.7)$ \\
Current & $19(45.2)$ \\
Former & $3(7.1)$ \\
Never & \\
\hline Time since diagnosis: $N(\%)$ & $27(64.3)$ \\
$<1$ to 4 years & $15(35.7)$ \\
$\leq 4$ to 9 years & \\
\hline Tumor site: $N(\%)$ & $20(47.6)$ \\
Oral cavity & $22(52.4)$ \\
Pharynx/Larynx & \\
\hline Cancer stage: $N(\%)$ & $12(28.6)$ \\
I-II & $30(71.4)$ \\
III-IV & \\
\hline Treatment: $N(\%)$ & $26(61.9)$ \\
Concurrent chemoradiation & $16(38.1)$ \\
Radiation only & \\
\hline Nutrition Impact Symptom Score & $15(35.7)$ \\
NIS $\leq 10$ & $27(64.3)$ \\
NIS $>$ 10 &
\end{tabular}

\subsection{Functional Status and Nutrition Impact Symptoms}

Table 2 reports the associations between functional status measures and the NIS summary score. A lower NIS summary score was statistically associated with higher post-treatment lean muscle mass $(p=0.002)$. A higher NIS summary score was nonstatistically associated with a higher post-treatment body mass index and functional status composite score.

Table 2. Nutrition impact symptom burden and associated quality of life and functional status outcomes in head and neck cancer survivors $N=42$.

\begin{tabular}{cccc}
\hline Quality of Life Outcome & Mean (SD) & Median & $p$-Value ${ }^{\text {a }}$ \\
\hline Functional QOL & & & \\
NIS $<10$ & $24.4(3.7)$ & 16.0 & $0.0006^{\mathrm{b}}$ \\
NIS $>10$ & $17.8(6.9)$ & 26.0 & \\
\hline Physical QOL & & & $0.0007^{\mathrm{b}}$ \\
NIS $<10$ & $25.1(2.6)$ & 26.0 & \\
NIS $>10$ & $20.5(5.8)$ & 21.0 & $0.007^{\mathrm{b}}$ \\
\hline Emotional QOL & & & \\
NIS $<10$ & $21.2(2.9)$ & 22.0 & 0.09 \\
NIS $>10$ & $18.5(3.8)$ & 19.0 & \\
\hline Social QOL & & 23.5 & $0.0001^{\mathrm{b}}$ \\
NIS $<10$ & $22.4(5.7)$ & 20.5 & \\
NIS $>10$ & $20.0(7.2)$ & & \\
\hline Total QOL & & 73.5 &
\end{tabular}


Table 2. Cont.

\begin{tabular}{cccc}
\hline Functional Status Outcome & Mean (SD) & Median & $p$-Value ${ }^{\mathbf{a}}$ \\
\hline Lean muscle mass $^{c}$ & & & \\
NIS $<10$ & $75.7(17.1)$ & 76.4 & $0.002^{\mathrm{b}}$ \\
NIS $>10$ & $59.9(15.0)$ & 55.8 & \\
\hline Body fat percentage $^{c}$ & & & \\
NIS $<10$ & $26.4(9.0)$ & 25.3 & \\
NIS $>10$ & $28.8(9.9)$ & 25.5 & \\
\hline Body mass index & & & \\
NIS $<10$ & $27.0(5.1)$ & 25.3 & \\
NIS $>10$ & $25.2(4.5)$ & 24.9 & \\
\hline Functional Status Score & & & \\
NIS $<10$ & $9.7(2.5)$ & 9.18 & \\
NIS $>10$ & $9.4(1.9)$ & &
\end{tabular}

${ }^{\mathrm{a}}$ Wilcoxon rank sum test; ${ }^{\mathrm{b}}$ Indicates statistical significance; ${ }^{\mathrm{c}} \mathrm{N}=38$.

\subsection{Quality of Life and Nutrition Impact Symptoms}

Table 2 also reports associations between quality of life measures and the NIS summary score. A lower NIS summary score was statistically associated with higher functional $(p=0.0006)$, physical $(p=0.0007)$, emotional $(p=0.007)$, and total $(<0.0001)$ quality of life.

\subsection{Mean Quality of Life Summary Score}

All FACT-H\&N mean summary scores and FACT-H\&N subscale scores were in the mild category (higher score), except for the Nutrition Impact Symptom Subscale (NIS) and Head and Neck Specific Concerns Subscale (HNCS) 6 item and 10 item, in which participants scored in the moderate category (Table 3).

Table 3. Functional Assessment Cancer Therapy (FACT) summary and subscale scores $N=42$.

\begin{tabular}{|c|c|c|c|c|c|}
\hline & \# Items & Actual Range & Observed Range & Mean (SD) & Impairment Category \\
\hline \multicolumn{6}{|c|}{ FACT summary scores } \\
\hline FACT-General & 27 & $0-108$ & $52-107$ & $85.31(15.21)$ & Mild \\
\hline FACT-Head and neck & 37 & $0-148$ & $65-135$ & $105.19(19.59)$ & Mild \\
\hline \multicolumn{6}{|c|}{ FACT subscale scores } \\
\hline Physical well-being & 7 & $0-28$ & $5-28$ & $22.90(4.91)$ & Mild \\
\hline Social well-being & 7 & $0-28$ & $0-28$ & $21.26(6.47)$ & Mild \\
\hline Emotional well-being & 6 & $0-24$ & $10-24$ & $19.90(3.58)$ & Mild \\
\hline Functional well-being & 7 & $0-28$ & $7-28$ & $21.24(6.34)$ & Mild \\
\hline Nutrition impact symptom questions & 6 & $0-24$ & $3-22$ & $12.93(5.26)$ & Moderate \\
\hline Head and neck specific concerns & 10 & $0-40$ & $7-32$ & $19.88(6.39)$ & Moderate \\
\hline
\end{tabular}

\subsection{Healthy Eating Index 2015 (HEI-2015) HNC Population vs. NHANES Data}

As compared to NHANES controls, HNC survivors reported a significantly lower total HEI-2015 diet quality score $(p=0.0001)$ (Table 4$)$. In the adequacy component, HNC survivors reported statistically significant lower consumption of total vegetables $(p<0.0001)$, whole grains $(p<0.01)$, total protein foods $(p<0.0001)$, seafood and plant proteins $(p<0.0001)$, and fatty acids $(p<0.0001)$. HNC survivors reported statistically significant higher consumption of dairy products $(p<0.01)$ and non-statistically significant higher consumption of total fruits and whole fruits. In the moderation component, HNC survivors consumed significantly more refined grains $(p<0.0001)$ and sodium $(p<0.0001)$, and significantly less added sugars $(p<0.0001)$ and saturated fats $(p<0.01)$ as compared to NHANES data. 
Table 4. Healthy Eating Index-2015 (HEI-2015) Carle HNC survivors vs. NHANES data.

\begin{tabular}{cccc}
\hline Component & $\begin{array}{c}\text { Actual Max } \\
\text { Points }\end{array}$ & $\begin{array}{c}\text { Carle HNC } \\
\text { Survivors } \\
\mathbf{N = 4 2}\end{array}$ & $\begin{array}{c}\text { Age-Matched } \\
\text { NHANES Population } \\
\text { 2015-2016 Data }\end{array}$ \\
\hline Total HEI Score & 100 & 54.3 & $\mathbf{6 0 . 6}^{\mathrm{b}}$ \\
\hline Total Fruits & 5 & Adequacy & \\
Whole Fruits & 5 & 2.9 & 2.8 \\
Total Vegetables & 5 & 3.2 & $4.4^{\mathrm{b}}$ \\
Greens and Beans & 5 & 2.1 & $3.8^{\mathrm{b}}$ \\
Whole Grains & 10 & 3.4 & $3.0^{\mathrm{c}}$ \\
Dairy & 10 & 2.5 & $5.4^{\mathrm{b}}$ \\
Total Protein Foods & 5 & 6.9 & $5.0^{\mathrm{b}}$ \\
Seafood and Plant Proteins & 5 & 3.0 & $5.0^{\mathrm{b}}$ \\
Fatty Acids & 10 & 3.0 & $4.5^{\mathrm{b}}$ \\
\hline & & 3.3 & $7.2^{\mathrm{b}}$ \\
\hline Refined Grains & 10 & & $3.7^{\mathrm{b}}$ \\
Sodium & 10 & 10.0 & $6.9^{\mathrm{b}}$ \\
Added Sugars & 10 & 8.9 & $5.3^{\mathrm{c}}$ \\
\hline Saturated Fats & 10 & 0.5 &
\end{tabular}

a Wilcoxon Rank Sum test to test difference; ${ }^{\mathrm{b}} p<0.0001 ;{ }^{\mathrm{c}} p<0.01$.

\section{Discussion}

To our knowledge, this study was among one of the first to explore the chronic complications of self-reported NIS burden on quality of life, objective measures of functional status, and diet quality in HNC survivors greater than 6 months post treatment. Notable findings were that higher post-treatment quality of life scores were associated with a lower NIS summary score (lower NIS burden). Furthermore, higher post-treatment lean muscle mass was associated with a lower NIS summary score, suggesting those who reported lower symptom burden had higher functional capacity. As compared to NHANES controls using the HEI-2015 population ratio method, HNC survivors in our study consumed a statistically significant lower total overall diet quality, which may be a result of NIS burden impacting the ability and desire to eat, though further longitudinal studies exploring this association are warranted.

Associations between quality of life measures and NIS were explored. Findings indicated that a lower NIS summary score was significantly associated with higher physical, functional, emotional, and total quality of life. Surprisingly, NIS burden was not associated with social quality of life for long-term survivors. A study by List et al. examining pretreatment coping strategies, reported that social support-seeking was the most common coping strategy used by patients with HNC and commonly begins immediately following diagnosis [35]. Therefore, it may be possible that quality of life outcomes, such as social well-being, improve in the months and years after treatment as it is likely long-term HNC survivors have had sufficient time to adapt to their new normal and seek social support groups [36].

Previous research has suggested self-reported impairments in functional performance are common in HNC survivors [37]. Despite their high prevalence, few multidisciplinary rehabilitation programs designed for HNC exist in the peer-reviewed literature, and in those studies, survivors were assessed during and immediately after treatment $[38,39]$. Our study was among one of the first to objectively measure functional status in post-treatment HNC survivors. Despite our small sample size, higher post-treatment lean muscle mass was associated with a lower NIS summary score. Furthermore, while our findings were not statistically significant, higher body mass index and functional status were non-statistically associated with a lower NIS summary score. Power calculations suggest a sample size of $N=80 \mathrm{HNC}$ survivors would detect a significant difference between the groups [40]. This 
work encourages larger, more robust clinical trials assessing risk factors for symptom development coupled with exercise and nutrition-based rehabilitation in long-term survivors to improve functional capacity.

Given the emphasis on the totality of the diet by national guidelines, our study team examined diet quality using the HEI-2015 among HNC cancer survivors as compared to NHANES data. HNC survivors reported a significantly lower total diet quality score as compared to NHANES controls, a possible consequence of treatment-related NIS burden. HNC survivors had higher diet quality scores among the adequacy component-dairy. As HNC survivors often experience difficulties with certain textures and flavors, we hypothesize this increase is likely due to HNC survivors' preference for soft foods, such as yogurt, which can be easily blended into smoothies and supplement drinks [41]. Additionally, the HNC population consumed nearly double the NHANES population for sodium and far less added sugars, likely a consequence of taste dysfunction resulting in food preference and aversion that is commonly reported in qualitative literature [2,4,42,43].

Limitations of this study should be noted. The cross-sectional design of the project is a limitation as quality of life and functional status measures were taken at only one time point. A prospective cohort study would be able to determine changes in different survivorship phases. Additionally, there is likely respondent bias inherent in the individuals in the individuals willing to complete the research study. The study population was selected from one Midwestern cancer center; consequently, the participants may not be fully representative of the total population of HNC survivors. The subjective bias of the FACT-H\&N is a limitation of the study. Because the direction of the relationship between symptom burden and quality of life is unclear, objective measures are needed to determine if symptoms, such as swallowing dysfunction, result in quality of life declines or if declining quality of life emphasizes perceived symptom burden. Additionally, while the NISs examined were from a validated quality of life questionnaire, the NIS summary score was created for this specific analysis and is not validated.

This pilot study consisted of $42 \mathrm{HNC}$ survivors. Although this study was severely underpowered, significant findings using simple Wilcoxon rank sum tests were noted. Furthermore, survivorship time ranged from 6 months to 10 years post treatment. Therefore, there was great heterogenicity in the population. A larger, longitudinal, and sufficiently powered study using multivariable regression models could further confirm directionality of quality of life, functional status, and diet quality changes post treatment based on this study's preliminary findings. Other strengths of the study include the use of validated questionnaires and objective measures of functional status in addition to the a priori approach to characterizing diet quality.

\section{Conclusions}

Self-reported NIS impairments were associated with lower quality of life and functional status outcomes among a population of long-term HNC survivors. As compared to an age-matched population from NHANES, HNC survivors reported lower overall diet quality, likely a result of symptoms impacting the ability and desire to eat. Multidisciplinary post-radiation exercise and nutrition-based interventions to manage NISs and improve quality of life, functional status, and dietary intake in this vulnerable survivor population are needed.

Author Contributions: S.L.C., K.P.S., and A.E.A. designed the study. S.L.C. and A.E.A. contributed to the development of the topic guide. S.L.C. collected the data. S.L.C. and Z.L. performed data analysis. S.L.C. wrote the first draft of the manuscript with contributions from all authors. All authors have read and agreed to the published version of the manuscript.

Funding: This study was supported by an Academy of Nutrition and Dietetics Colgate Palmolive Fellowship in Nutrition and Oral Health (PI: Crowder), USDA National Institute of Food and Agriculture, Hatch project 1011487 (PI: Arthur), a Division of Nutritional Sciences Vision 20/20 Grant PI: Arthur), and a Carle-Illinois Cancer Scholars for Translational and Applied Research Fellowship. SC was supported by NCI Cancer Prevention and Control Training Grant: 5T32CA090314- 
17 (MPIs: Brandon/Vadaparampil) and Carle Illinois Cancer Scholars for Translational and Applied Research Fellowship.

Institutional Review Board Statement: The study was conducted according to the guidelines of the Declaration of Helsinki, and approved by the Institutional Review Board Institutional Review Boards of Carle Foundation Hospital and the University of Illinois at Urbana-Champaign (Project ID: 17088; UIUC number: 181933; Original Approval Date: 1 February 2018).

Informed Consent Statement: Informed consent was obtained from all subjects involved in the study.

Data Availability Statement: The dataset generated and analyzed in the current study are not publicly available due to the sensitive nature of responses, but deidentified data are available from the corresponding author on reasonable request.

Acknowledgments: The authors would like to thank Ozette Ostrow for assisting with data collection.

Conflicts of Interest: The authors declare no conflict of interest.

\section{References}

1. UM Head and Neck SPORE Program; Arthur, A.E.; Peterson, E.K.; Rozek, L.S.; Taylor, J.M.G.; Light, E.; Chepeha, D.; Hébert, J.R.; Terrell, J.E.; Wolf, G.T.; et al. Pretreatment dietary patterns, weight status, and head and neck squamous cell carcinoma prognosis. Am. J. Clin. Nutr. 2013, 97, 360-368.

2. Crowder, S.L.; Douglas, K.G.; Pepino, M.Y.; Sarma, K.P.; Arthur, A.E. Nutrition impact symptoms and associated outcomes in post-chemoradiotherapy head and neck cancer survivors: A systematic review. J. Cancer Surviv. 2018, 12, 479-494. [CrossRef]

3. Payakachat, N.; Ounpraseuth, S.; Suen, J.Y. Late complications and long-term quality of life for survivors ( $>5$ years) with history of head and neck cancer. Head Neck 2013, 35, 819-825. [CrossRef] [PubMed]

4. Ganzer, H.; Rothpletz-Puglia, P.; Byham-Gray, L.; Murphy, B.A.; Touger-Decker, R. The eating experience in long-term survivors of head and neck cancer: A mixed-methods study. Support. Care Cancer 2015, 23, 3257-3268. [CrossRef]

5. Nguyen, N.-T.A.; Ringash, J. Head and Neck Cancer Survivorship Care: A Review of the Current Guidelines and Remaining Unmet Needs. Curr. Treat. Options Oncol. 2018, 19, 44. [CrossRef]

6. Howren, M.B.; Christensen, A.J.; Karnell, L.H.; Van Liew, J.R.; Funk, G.F. Influence of pretreatment social support on health-related quality of life in head and neck cancer survivors: Results from a prospective study. Head Neck 2012, 35, 779-787. [CrossRef]

7. Papadakos, J.; McQuestion, M.; Gokhale, A.; Damji, A.; Trang, A.; Abdelmutti, N.; Ringash, J. Informational Needs of Head and Neck Cancer Patients. J. Cancer Educ. 2018, 33, 847-856. [CrossRef]

8. Ringash, J. Survivorship and Quality of Life in Head and Neck Cancer. J. Clin. Oncol. 2015, 33, 3322-3327. [CrossRef] [PubMed]

9. Taylor, J.C.; Terrell, J.E.; Ronis, D.L.; Fowler, K.; Bishop, C.; Lambert, M.T.; Myers, L.L.; Duffy, S.A. Disability in Patients With Head and Neck Cancer. Arch. Otolaryngol. Head Neck Surg. 2004, 130, 764-769. [CrossRef] [PubMed]

10. Leeuw, I.M.V.-D.; Van Bleek, W.-J.; Leemans, C.R.; De Bree, R. Employment and return to work in head and neck cancer survivors. Oral Oncol. 2010, 46, 56-60. [CrossRef]

11. Koch, R.; Wittekindt, C.; Altendorf-Hofmann, A.; Singer, S.; Guntinas-Lichius, O. Employment pathways and work-related issues in head and neck cancer survivors. Head Neck 2014, 37, 585-593. [CrossRef]

12. Isaksson, J.; Wilms, T.; Laurell, G.; Fransson, P.; Ehrsson, Y.T. Meaning of work and the process of returning after head and neck cancer. Support. Care Cancer 2015, 24, 205-213. [CrossRef] [PubMed]

13. Nelke, K.H.; Pawlak, W.; Gerber, H.; Leszczyszyn, J. Head and neck cancer patients' quality of life. Adv. Clin. Exp. Med. 2014, 23, 1019-1027. [CrossRef] [PubMed]

14. Cartmill, B.; Cornwell, P.; Ward, E.; Davidson, W.; Porceddu, S. Long-term Functional Outcomes and Patient Perspective Following Altered Fractionation Radiotherapy with Concomitant Boost for Oropharyngeal Cancer. Dysphagia 2012, 27, 481-490. [CrossRef] [PubMed]

15. Crowder, S.L.; Najam, N.; Sarma, K.P.; Fiese, B.H.; Arthur, A.E. Head and Neck Cancer Survivors' Experiences with Chronic Nutrition Impact Symptom Burden after Radiation: A Qualitative Study. J. Acad. Nutr. Diet. 2020, 120, 1643-1653. [CrossRef]

16. Krebs-Smith, S.M.; Pannucci, T.E.; Subar, A.F.; Kirkpatrick, S.I.; Lerman, J.L.; Tooze, J.A.; Wilson, M.M.; Reedy, J. Update of the Healthy Eating Index: HEI-2015. J. Acad. Nutr. Diet. 2018, 118, 1591-1602. [CrossRef] [PubMed]

17. Willett, W. Monographs in epidemiology and biostatistics. In Nutritional Epidemiology, 3rd ed.; Oxford University Press: New York, NY, USA, 2013; 529p.

18. National Cancer Institute. Population Ratio Method. Available online: https://epi.grants.cancer.gov/hei/population-ratiomethod.html (accessed on 3 March 2020).

19. Rimm, E.B.; Giovannucci, E.L.; Stampfer, M.J.; Colditz, G.A.; Litin, L.B.; Willett, W.C. Reproducibility and Validity of an Expanded Self-Administered Semiquantitative Food Frequency Questionnaire among Male Health Professionals. Am. J. Epidemiol. 1992, 135, 1114-1126, discussion 1127-1136. [CrossRef]

20. Willett, W.C.; Sampson, L.; Stampfer, M.J.; Rosner, B.; Bain, C.; Witschi, J.; Hennekens, C.H.; Speizer, F.E. Reproducibility and validity of a semiquantitative food frequency questionnaire. Am. J. Epidemiol. 1985, 122, 51-65. [CrossRef] [PubMed] 
21. Rogers, L.Q.; Anton, P.M.; Bs, A.F.; Hopkins-Price, P.; Verhulst, S.; Rao, K.; Malone, J.; Robbs, R.; Courneya, K.S.; Nanavati, P.; et al. Pilot, randomized trial of resistance exercise during radiation therapy for head and neck cancer. Head Neck 2013, 35, 1178-1188. [CrossRef]

22. Böhm, A.; Heitmann, B.L. The use of bioelectrical impedance analysis for body composition in epidemiological studies. Eur. J. Clin. Nutr. 2013, 67 (Suppl. S1), S79-S85. [CrossRef]

23. List, M.A.; D'Antonio, L.L.; Cella, D.F.; Siston, A.; Mumby, P.; Haraf, D.; Vokes, E. The performance status scale for head and neck cancer patients and the functional assessment of cancer therapy-head and neck scale: A study of utility and validity. Cancer 1996, 77, 2294-2301. [CrossRef]

24. Lohman, T.G.; Roche, A.F.; Martorell, R. Anthropometric Standardization Reference Manual; Human Kinetics Books: Champaign, IL, USA, 1988.

25. Guralnik, J.M.; Simonsick, E.M.; Ferrucci, L.; Glynn, R.J.; Berkman, L.F.; Blazer, D.G.; Scherr, P.A.; Wallace, R.B. A Short Physical Performance Battery Assessing Lower Extremity Function: Association with Self-Reported Disability and Prediction of Mortality and Nursing Home Admission. J. Gerontol. 1994, 49, M85-M94. [CrossRef]

26. Harvard school of public health. Harvard School of Public Health Nutrition Department's file download site. Available online: https: / regepi.bwh.harvard.edu/health/FFQ/ files (accessed on 21 August 2021).

27. Willett, W. Nutrient Epidemiology; Oxford Press: New York, NY, USA, 1998.

28. Data-National Center for Health Statistics. Healthy Eating Index-2015 Scores-U.S. Department of Agriculture, Center for Nutrition Policy and Promotion. Available online: https: / www.fns.usda.gov/healthy-eating-index-hei (accessed on 11 February 2020).

29. National Cancer Institute. Healthy Eating Index: Overview of the Methods and Calculations. Available online: https://epi. grants.cancer.gov/hei/hei-methods-and-calculations.html (accessed on 14 February 2020).

30. Guenther, P.M.; Reedy, J.; Krebs-Smith, S.M. Development of the Healthy Eating Index-2005. J. Am. Diet. Assoc. 2008, 108, 1896-1901. [CrossRef]

31. Webster, K.; Cella, D.; Yost, K. The Functional Assessment of Chronic Illness Therapy (FACIT) Measurement System: Properties, applications, and interpretation. Health Qual. Life Outcomes 2003, 1, 79. [CrossRef]

32. Fisch, M.J.; Titzer, M.L.; Kristeller, J.L.; Shen, J.; Loehrer, P.J.; Jung, S.-H.; Passik, S.D.; Einhorn, L.H. Assessment of Quality of Life in Outpatients With Advanced Cancer: The Accuracy of Clinician Estimations and the Relevance of Spiritual Well-Being-A Hoosier Oncology Group Study. J. Clin. Oncol. 2003, 21, 2754-2759. [CrossRef]

33. Bilal, S.; Doss, J.G.; Cella, D.; Rogers, S.N. Quality of life associated factors in head and neck cancer patients in a developing country using the FACT-H\&N. J. Cranio Maxillofac. Surg. 2015, 43, 274-280.

34. SAS. 9.4 [Computer Program]; SAS: Cary, NC, USA, 2014.

35. List, M.A.; Rutherford, J.L.; Stracks, J.; Haraf, D.; Kies, M.S.; Vokes, E.E. An exploration of the pretreatment coping strategies of patients with carcinoma of the head and neck. Cancer 2002, 95, 98-104. [CrossRef] [PubMed]

36. Feinstein, A.R. Multi-item “instruments” vs Virginia Apgar's principles of clinimetrics. Arch. Intern. Med. 1999, 159, 125-128. [CrossRef]

37. van Deudekom, F.J.; Schimberg, A.S.; Kallenberg, M.H.; Slingerland, M.; van der Velden, L.-A.; Mooijaart, S.P. Functional and cognitive impairment, social environment, frailty and adverse health outcomes in older patients with head and neck cancer, a systematic review. Oral Oncol. 2017, 64, 27-36. [CrossRef] [PubMed]

38. Ringash, J.; Bernstein, L.; Devins, G.; Dunphy, C.; Giuliani, M.; Martino, R.; McEwen, S. Head and Neck Cancer Survivorship: Learning the Needs, Meeting the Needs. Semin. Radiat. Oncol. 2018, 28, 64-74. [CrossRef]

39. Capozzi, L.C.; Nishimura, K.C.; McNeely, M.; Lau, H.; Culos-Reed, S.N. The impact of physical activity on health-related fitness and quality of life for patients with head and neck cancer: A systematic review. Br. J. Sports Med. 2016, 50, 325-338. [CrossRef]

40. Faul, F.; Erdfelder, E.; Lang, A.-G.; Buchner, A. G*Power 3: A flexible statistical power analysis program for the social, behavioral, and biomedical sciences. Behav. Res. Methods 2007, 39, 175-191. [CrossRef] [PubMed]

41. Kristensen, M.B.; Mikkelsen, T.B.; Beck, A.M.; Zwisler, A.-D.; Wessel, I.; Dieperink, K.B. To eat is to practice-managing eating problems after head and neck cancer. J. Cancer Surviv. 2019, 13, 792-803. [CrossRef]

42. Larsson, M.; Hedelin, B.; Athlin, E. Lived experiences of eating problems for patients with head and neck cancer during radiotherapy. J. Clin. Nurs. 2003, 12, 562-570. [CrossRef] [PubMed]

43. Bressan, V.; Bagnasco, A.; Aleo, G.; Catania, G.; Zanini, M.; Timmins, F.; Sasso, L. The life experience of nutrition impact symptoms during treatment for head and neck cancer patients: A systematic review and meta-synthesis. Support. Care Cancer 2017, 25, 1699-1712. [CrossRef] [PubMed] 